\title{
Detecting trends in desert tortoise population growth: elusive behavior inflates variance in estimates of population density
}

\author{
Richard D. Inman ${ }^{1,2}$, Kenneth E. Nussear ${ }^{1, *}$, C. Richard Tracy ${ }^{2}$ \\ ${ }^{1}$ Western Ecological Research Center, United States Geologic Survey, Las Vegas Field Station, 160 N Stephanie St, \\ Henderson, Nevada 89074-8829, USA \\ ${ }^{2}$ Department of Biology, University of Nevada, 1664 N. Virginia St., Reno, Nevada 89557-0001, USA
}

\begin{abstract}
Assessing the recovery of the federally listed Mojave population of desert tortoises Gopherus agassizii requires detecting subtle changes in population size over a period of many years. The methods that have been employed by the US Fish and Wildlife Service to estimate population density of desert tortoises are inadequate for detecting modest trends in population density, partly due to a hidden variance in a parameter $\left(g_{0}\right)$ that corrects for the proportion of tortoises that are inactive and thus unavailable for sampling when population density is being assessed. We used small dataloggers to record the activity of tortoises throughout their active season, and derived daily estimates of $g_{0}$, which we compared with the 2004 estimate published by the US Fish and Wildlife Service. Due to the substantial variation in animal activity that we found within and among days during the active season, we used a daily method to estimate density. We found that this method, while providing a more accurate assessment of $g_{0}$, translates into estimates of density with coefficients of variation that are $4 \times$ larger than previously reported due to the variation in $g_{0}$ and $\mathrm{n}$ (number of animals encountered). This discrepancy could adversely influence managers' perceptions of population recovery for desert tortoises, and could undermine any ability to monitor the efficacy of recovery actions for populations.
\end{abstract}

KEY WORDS: Desert tortoise - Gopherus agassizii · Monitoring · Distance $\cdot$ Population trend · Abundance $\cdot$ Detection probability $\cdot$ Sampling availability $\cdot$ Biologging

\section{INTRODUCTION}

Desert tortoises Gopherus agassizii are long-lived terrestrial reptiles that live throughout the Mojave Desert in parts of Utah, Nevada, Arizona and California, USA (Germano et al. 1994). Due to documented declines in desert tortoise populations, the Mojave population (tortoises north and west of the Colorado River) was emergency listed under the US Endangered Species Act as endangered in 1989, with a subsequent listing as threatened in 1990 (US Fish and Wildlife Service 1989, 1990). Desert tortoise populations are characterized by having low potential growth rates that range from $0.25 \%$ to a maximum of $2 \% \mathrm{yr}^{-1}$, with a theoretical mean population growth rate of 0.8 to $1.15 \% \mathrm{yr}^{-1}$ (US Fish and Wildlife Service 1994). In addition to this very low potential growth rate, the density (and size) of desert tortoise populations affects their time to extinction, such that populations with low densities are in greater danger of extinction than those with higher densities (Green \& Young 1993, Lande 1993, US Fish and Wildlife Service 1994). Research and monitoring to assess the status and population dynamics of this species were initiated in the late 1970s using mark-recapture techniques on a few dozen study plots (Berry 1984, Germano et al. 1994, US Fish and Wildlife Service 1994), and continues with the addition of a range-wide monitoring program using distance sampling methods that were established in 2001 (Anderson et al. 2001, US Fish and Wildlife Service 2006). Desert tortoises have continued to show declining numbers, and in some regions where densities of $\geq 60$ tortoises 
$\mathrm{km}^{-2}$ were once common on study plots (Berry 1984, Tracy et al. 2004), current estimates range from 1 to 12 tortoises $\mathrm{km}^{-2}$ (US Fish and Wildlife Service 2006). Measuring recovery of this species requires (among other things) detecting modest growth in population density (US Fish and Wildlife Service 1994, 2008). The current range-wide program that has been implemented to detect population trends relies on knowledge of the behavior of individuals in a population (Anderson et al. 2001), which can be difficult to attain.

Desert tortoises are cryptically colored and fossorial, which frequently causes them to be elusive to sampling when they are hidden from view in dense vegetation, in rocky terrain, and in underground burrows (Nussear \& Tracy 2007); thus, individuals are often missed during surveys (Corn 1994, Germano et al. 1994, Bury \& Corn 1995). Because of this, monitoring desert tortoises requires knowledge of what determines activity patterns in this species (Freilich et al. 2000, Anderson et al. 2001). Extensive research on how activity patterns of individuals are related to the thermal environment (Zimmerman et al. 1994, Duda et al. 1999, Wilson et al. 1999, Bulova 2002) has shown that desert tortoises exploit the heterogeneity of their thermal environment to achieve particular body temperatures, and avoid thermal extremes by retreating to underground burrows and dense vegetation (Woodbury \& Hardy 1948, Zimmerman et al. 1994). Although these behaviors are well documented, few studies have quantified the effects of this elusive behavior on estimates of population densities derived from transect sampling methods.

Transect sampling is currently employed by the US Fish and Wildlife Service (hereafter FWS) using the program Distance (Buckland et al. 2001) to estimate range-wide and regional population densities of desert tortoises. This method includes 2 parameters intended to correct density estimates for (1) the decreasing detectability of tortoises by surveyors at increasing distances from the transect ( $P_{a}$ Buckland et al. 2001), and (2) tortoises on the transect that are missed because they are in locations where they cannot be seen and sampled, such as in underground burrows $\left(g_{0}\right.$; Anderson et al. 2001). Both $g_{0}$ and $P_{a}$ are proportions with finite ranges from 0 to 1 . These 2 parameters frequently change in time and space, and impart uncertainty in the estimate of population density (Buckland et al. 2004).

While methods for estimating $P_{a}$ (and its error) have been thoroughly discussed elsewhere (Buckland 1985, Buckland et al. 2001, 2004), methods for estimating the $g_{0}$ parameter have only been briefly addressed (Thompson 2002, Laake \& Borchers 2004), and the $g_{0}$ parameter is not often used with Distance sampling (Bächler \& Liechti 2007). This parameter and its SE have been estimated in past years (for desert tortoise monitoring) by assessing the activity of several small samples of individuals (groups) in different sampling localities, which are monitored periodically using VHF radio-telemetry during the times when transect sampling occurs (US Fish and Wildlife Service 2006). Individuals in each of these small groups are radio-tracked and observed 10 to 20 times during the transect sampling period (typically 1 April to 1 June, US Fish and Wildlife Service 2006). A single range-wide estimate of $g_{0}$ is derived by taking the mean of each animal's averaged activity during the entire transect sampling period, and the SE is estimated by taking the SD of activity estimates of all radio-tracked individuals (US Fish and Wildlife Service 2006).

One problem with this approach to estimating $g_{0}$ is that the activity of a population of tortoises can be significantly misrepresented when the sample size of individuals is small (Nussear \& Tracy 2007). A sample size of at least 20 ind. may be needed to assess the activity in a large population (Nussear \& Tracy 2007). During the first $5 \mathrm{yr}$ of sampling, FWS used several samples with 8 to 12 ind., resulting in imprecise and potentially inaccurate estimates of $g_{0}$. However, while using larger sample sizes to estimate the activity of desert tortoises would produce a more realistic estimate of the $g_{0}$ parameter and its $\mathrm{CV}$, a method that estimates the variation 'throughout' time is likely to be more important because $g_{0}$ varies substantially from day to day and from hour to hour throughout each day of the sampling period. Unfortunately, the program Distance (Thomas et al. 2004) is currently not designed to incorporate daily estimates of $g_{0}$. Instead, a single pooled value of $g_{0}$ has been used by FWS to scale density estimates, and the SE of this parameter is used (among other sources of variance, such as $P_{a}$ and $\mathrm{n}$ (the number of animals encountered along transects)) to estimate the precision of the density estimate (Buckland et al. 2001).

We used a different approach to quantify $g_{0}$ by measuring the daily activity of 34 tortoises in the Western Mojave Recovery Unit at short time intervals throughout the sampling season in 2004. Data on the nanoclimates (the climate immediately surrounding the tortoise) experienced by tortoises (as measured using small sensors and dataloggers attached to the animals) were used to develop a model that predicted tortoise activity during the sampling period from interactions between desert tortoises and their nanoclimates. Using the predicted activity data from our study animals, we estimated the $g_{0}$ parameter and its $\mathrm{CV}$ at several time scales for the entire sampling season. We investigated whether daily estimates of $g_{0}$ have a different effect on the accuracy and precision of density estimates compared to pooled estimates of $g_{0}$ by implementing an 
estimate of density for the Western Mojave Recovery Unit; this estimate is calculated from daily estimates of density with a daily $g_{0}$ correction being applied. Finally, we assessed the extent to which previous methods used by the FWS to estimate $g_{0}$ may be insufficient in accounting for variation in the behavior of desert tortoises, and to what extent these methods may affect the precision of density estimates.

\section{MATERIALS AND METHODS}

Field sites. Tortoises were studied at 2 sites located in the western Mojave Desert in the Superior-Cronese and Ord-Rodman desert wildlife management areas (DWMAs) of the Western Mojave Recovery Unit for desert tortoises. The sites are approximately $16 \mathrm{~km}$ northwest and $64 \mathrm{~km}$ southeast of Barstow, California, respectively. Each site is located in a valley characterized by Mojave Desert scrub (Turner 1982) with only moderate topographic relief. Populations at these sites were used to estimate $g_{0}$ as part of the FWS desert tortoise monitoring program from 1999 to 2008.

Behavioral observations. Thirty-four adult desert tortoises from the 2 sites described above were previously equipped with radio-transmitters and were monitored intensively from 1 April to 1 June 2004. Miniature dataloggers (HOBO H8 Temp/RH/Light, Onset) were used to record the nanoclimate experienced by each tortoise as it moved among microhabitats. Each logger was $4.5(\mathrm{l}) \times 3(\mathrm{w}) \times 0.75(\mathrm{~h}) \mathrm{cm}$ in size, and was $\sim 50 \mathrm{~g}$ in mass when epoxy was applied ( $\sim 0.05 \%$ of an individual's mass). The outer plastic case of each commercial datalogger was removed and the circuitry was re-sealed in heat-shrunk tubing to decrease the volume and mass of the datalogger and to streamline its shape. Each datalogger recorded light intensity $\left(\mathrm{lm} \mathrm{\textrm {ft } ^ { - 2 }}\right)$, absolute humidity $\left(\mathrm{g} \mathrm{m}^{-3}\right)$, and temperature $\left({ }^{\circ} \mathrm{C}\right)$ as measured above the tail of the tortoise (Nussear et al. 2002). The datalogger was attached to the carapace on either the 5th vertebral, 5th right, or 5 th left costal scute, depending on the size and shape of the animal. This attachment site was chosen to minimize interference with the animal's behavior, and to provide maximum exposure of each of the sensors to the environment. No dataloggers were lost prematurely, and all were recovered at the end of the study. Each datalogger recorded data at 15 min intervals, and data were retrieved every 2 wk throughout the study. An additional datalogger was placed on the ground surface to measure the surface conditions that a tortoise would experience at each site.

Light intensity from the datalogger on the ground surface was compared to that from each animal and was reclassified into a multinomial variable indicating whether or not the sensor was exposed to sunlight, where a value of -1 indicated that the animal was not exposed to light even though the surface was (e.g. it was daytime and the animal was in a burrow), a value of 0 indicated that both the animal and the datalogger experienced similar light levels (e.g. it was daytime and the animal was above ground, or it was night time and the animal was either above or below ground), and a value of +1 indicated that the animal experienced light when the datalogger on the ground surface did not. This last condition was rare and was likely due to shade obscuring the (surface) datalogger from the early morning or late evening sunlight.

Behavioral observations of each individual were taken 2 to 6 times per day during each of the 10 observation periods throughout the study, and each observation period lasted from 1 to $3 \mathrm{~d}$ at each site. Each time an animal was observed, its activity and microhabitat position (above or below ground) was assessed and recorded. Behavioral observations were made from the furthest distance possible (usually ranging from 5 to $15 \mathrm{~m}$ ) to assess the microhabitat position of each individual, and animals were observed for $<30 \mathrm{~s}$ at each encounter to minimize the impact of observer presence. Behavioral observations similar to this method have been used in several previous studies with little or no effect on animal behavior (Bulova 1994, Zimmerman et al. 1994, Nussear \& Tracy 2007).

An artificial neural network (NeuroSolutions 5.0, Neurodimension) was used to classify the nanoclimate experienced by each individual into above or below ground positions using data pooled from both sites. A random sample of $40 \%$ of all observations was withheld from the training process of model development in order to test each model with the independent data. The Kappa coefficient of agreement was used to measure the overall performance of the model (Fielding \& Bell 1997), and a confusion matrix was used to identify which of the microhabitats (below ground in a burrow or above ground) was better predicted by the model. The model was used to predict tortoise activity (above or below ground) for each $15 \mathrm{~min}$ interval from 05:00 $\mathrm{h}$ to 19:00 $\mathrm{h}$ (Pacific daylight saving time, PDST) from 1 April to 1 June, resulting in $\sim 57$ predictions $\mathrm{d}^{-1}$ of each tortoise's microhabitat position.

West Mojave density estimates. We derived an estimate of density, $D$, for the Western Mojave Recovery Unit using a modified version of the density equation developed for sampling desert tortoise populations (Anderson et al. 2001), where the density estimate was taken as the average of daily estimates of density calculated with daily estimates of the $g_{0}$ parameter $\left(g_{0 \mathrm{~d}}\right)$, the number of tortoises encountered each day $\left(\mathrm{n}_{\mathrm{d}}\right)$ and the length of transect walked each day $\left(l_{\mathrm{d}}\right)$ : 


$$
\mathrm{d}=1 \sum_{\mathrm{d}_{1} \ldots \mathrm{d}_{N}}^{N}\left(\frac{\mathrm{n}_{\mathrm{d}}}{l_{\mathrm{d}} \times W}\right) \times\left(\frac{1}{P_{\mathrm{a}} \times g_{0 \mathrm{~d}}}\right)
$$

where $N$ is the total number of days sampled, $\mathrm{d}_{1} \ldots \mathrm{d}_{N}$ is the index of unique days over which the mean density is calculated, $W$ is the effective width of transects, and $P_{a}$ is the detection probability. The CV of the density estimate was calculated as:

$\mathrm{CV}(D)=\frac{1}{N} \sum_{\mathrm{d}_{1} \ldots \mathrm{d}_{N}}^{N} \sqrt{\left[\mathrm{CV}(\mathrm{n})_{\mathrm{d}}\right]^{2}+\left[\mathrm{CV}\left(P_{a}\right)_{\mathrm{d}}\right]^{2}+\left[\mathrm{CV}\left(g_{0}\right)_{\mathrm{d}}\right]^{2}}$

Each daily estimate of $g_{0}$ was defined as:

$$
g_{0, \mathrm{~d}}=\frac{1}{57} \frac{1}{34} \sum_{\mathrm{o}=1}^{57} \sum_{t=1}^{34} \mathrm{a}_{\mathrm{o}, \mathrm{s}, \mathrm{d}}
$$

where $a=$ activity at each observation (o) for each study animal (s) on a given day (d). The coefficient of variation of $\mathrm{g}_{0, \mathrm{~d}}$ is denoted as $\mathrm{SE}\left(\mathrm{g}_{0, \mathrm{~d}}\right) / \mathrm{g}_{0 \mathrm{~d}}$.

The CV(n) for each day (d) was defined as:

$$
\operatorname{CV}\left(\mathrm{n}_{\mathrm{d}}\right)=\sqrt{\left(\frac{L_{\mathrm{d}} \sum_{t=1}^{k_{\mathrm{d}}} l_{\mathrm{t}, \mathrm{d}}\left(\mathrm{n}_{\mathrm{t}, \mathrm{d}} / 1_{\mathrm{t}, \mathrm{d}}-\mathrm{n}_{\mathrm{d}} / L_{\mathrm{d}}\right)^{2}}{k_{\mathrm{d}}-1} / \mathrm{n}_{\mathrm{d}}{ }^{2}\right)}
$$

where the length of each transect $\left(l_{t, d}\right)$, total length of all transects for each day $\left(L_{\mathrm{d}}\right)$, total number of encounters for each day $\left(\mathrm{n}_{\mathrm{d}}\right)$, and total number of transects surveyed on a given day $\left(k_{\mathrm{d}}\right)$ were were calculated from published transect data (US Fish and Wildlife Service 2006).

Differences between our estimate of density for the 2004 sampling year for the Western Mojave Recovery Unit and that published for the same year (US Fish and Wildlife Service 2006) were evaluated using a Z-test for differences among means. Similarly, the differences between the CVs of these estimates of density were compared using a Z-test for CVs (Miller 1991).

Theoretical variance of $\boldsymbol{g}_{\mathbf{0}}, \mathbf{n}$, and $\boldsymbol{P}_{\boldsymbol{a}}$. We used Eq. (2) to calculate the simultaneous influence of the CVs of $g_{0}, \mathrm{n}$, and $P_{a}$ on the CV of $D$ by allowing each of the parameters to vary within an expected range that was defined by activity data or published values (US Fish and Wildlife Service 2006) for the first $5 \mathrm{yr}$ of sampling.

The expected range of the CVs of $g_{0}$ was defined using the activity data from our study animals to estimate the minimum and maximum CVs that would result from sampling on consecutive days of varying lengths. We assumed that sampling could be completed for the West Mojave in 5 to 25 consecutive days during the active season, and therefore took samples of our activity data during the months of April and May, of $N$ days in length to estimate $g_{0}$, where $N$ ranged from 5 to $25 \mathrm{~d}$. We used the estimated $g_{0}$ value (from Eq. 3) for each day, and the minimum and maximum
CVs of $g_{0}$ from all sample sizes of $N$ to represent the minimum and maximum CVs possible under existing sampling conditions, which ranged from 0.16 to 0.74 .

We used published transect and encounter data from 2004 to estimate the CV of $\mathrm{n}$ for each day that transect sampling was conducted; this allowed us to determine the minimum and maximum CVs of $n$ that were possible under existing sampling conditions. This gave a range of near 0.1 to 0.6 , and therefore we held the $\mathrm{CV}$ of $\mathrm{n}$ constant at 3 levels $(0.1,0.4$, and 0.7$)$, which bounded the range of CVs possible when estimating density.

The upper and lower limits to the expected ranges of CVs for $g_{0}, P_{a}$ and the 3 levels of CV for n were subsequently used to estimate the upper and lower limits of the precision of density estimates that could be expected under conditions similar to the first $5 \mathrm{yr}$ of sampling.

Estimates of density with CVs of $<0.125,0.25,0.35$, 0.45 or 0.55 were identified previously as the thresholds where distance sampling would show sufficient precision to identify $1,2,3,4$ or $5 \%$ annual trends in desert tortoise population size over a $25 \mathrm{yr}$ period, respectively (Nussear \& Tracy 2007). We used these thresholds to identify combinations of the CVs of $g_{0}$ and $P_{a}$ where distance sampling could detect the same $(1,2,3,4$ or $5 \%)$ annual trends. However, this method assumed that the covariance between $\mathrm{n}, g_{0}$ and $P_{a}$ was 0 , and treated each as an independent random variable. While this assumption is probably incorrect $\left(g_{0}\right.$, $P_{a}$ and $\mathrm{n}$ are likely to be linked under certain conditions), few data are available to estimate their covariance across many years and habitat types.

\section{RESULTS}

\section{Activity model}

An artificial neural network model including body temperature $\left(T_{\mathrm{bi}}{ }^{\circ} \mathrm{C}\right)$, absolute humidity of the nanoclimate of the tortoise $\left(\mathrm{ABSH}_{\mathrm{o}} ; \mathrm{g} \mathrm{m}^{-3}\right)$, light intensity on

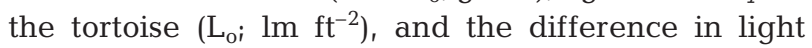
intensity between the surface and the tortoise provided the best fit among the models we investigated; this model was subsequently used to classify tortoise nanoclimates for each 15 min interval into above- or below-ground microhabitat positions (i.e. presence of the tortoise on the surface of the ground, or in a retreat site such as a burrow or other place not on the surface) suitable for estimating $g_{0}$. The resulting model predicted below-ground and above-ground activity about equally well (91 and $89 \%$ accuracy for below-ground and above-ground activity, respectively), and had a Kappa of 0.795. 


\section{Variation in tortoise activity}

The above-ground activity (interpreted from dataloggers) of tortoises varied throughout the activity season, with higher levels of surface activity in April than in May. Daily activity decreased throughout the season until the end of the study in June (Fig. 1A). In general, activity in April was greater than in May, with 50 to $90 \%$ of animals assessed as being above the ground during the month of April. The CVs of $g_{0}$ generally increased throughout the sampling period, with the highest CV occurring when activity was lowest at the end of May (Fig. 1B). In contrast, the CVs of $\mathrm{n}$ reported from FWS transect data remained relatively consistent across all days when transect sampling was conducted (Fig. 1C).

Animals were generally not as active during the early morning and late evening hours (especially in mid to late May), when seasonal averages of hourly activity were as low as 20 to $40 \%$ being above groundin the early morning (05:00 to 07:00 h) and late evening (17:00 to 19:00 h; Fig. 2). On days when transect sampling was conducted by FWS (2-7 April, 12 April, 21-26 April and 2-3 May), tortoise activity ranged from 50 to $90 \%$ of the total population being above ground (Fig. 1A). The pooled and range-wide value of $g_{0}$ estimated by the FWS (0.864) was always higher than the measured values at our sites in the Western Mojave Desert (Fig. 1A).

\section{Density estimates}

Our estimate of density $\left(D_{\text {daily }}=5.27\right.$ tortoises $\mathrm{km}^{-2}$, $\mathrm{CV}=53.0 \%$ ) derived from daily estimates of density for the Western Mojave Recovery Unit in 2004 was not significantly different $\left(Z_{2}=0.015, \mathrm{p}=0.49\right)$ from the published estimate of density (5.31 tortoises $\mathrm{km}^{-2}, \mathrm{CV}=$ $12.5 \%$, US Fish and Wildlife Service 2006). However, because we estimated density for each day that transect sampling was conducted, and thus had fewer encounters and fewer kilometers of transects walked in each of our daily estimates of density than did the pooled estimate used by FWS, the CV of $\mathrm{n}$ for each day was higher than the pooled estimate of $n$ used in the published estimate of density (US Fish and Wildlife Service 2006). The increased CVs of $\mathrm{n}$ and $g_{0}$ caused our CV for the estimate of density to be significantly $\left(Z_{2}=12.903, p=\right.$ 0 ) higher than the $\mathrm{CV}$ of the density estimate reported for the Western Mojave Recovery Unit in 2004 (53.0 vs. $12.5 \%$; US Fish and Wildlife Service 2006).

\section{Theoretical variance of $g_{0}, \mathbf{n}$, and $\boldsymbol{P}_{\mathrm{a}}$}

We found that the largest influences on the $\mathrm{CV}$ accepted for $g_{0}$ were the date on which the sampling
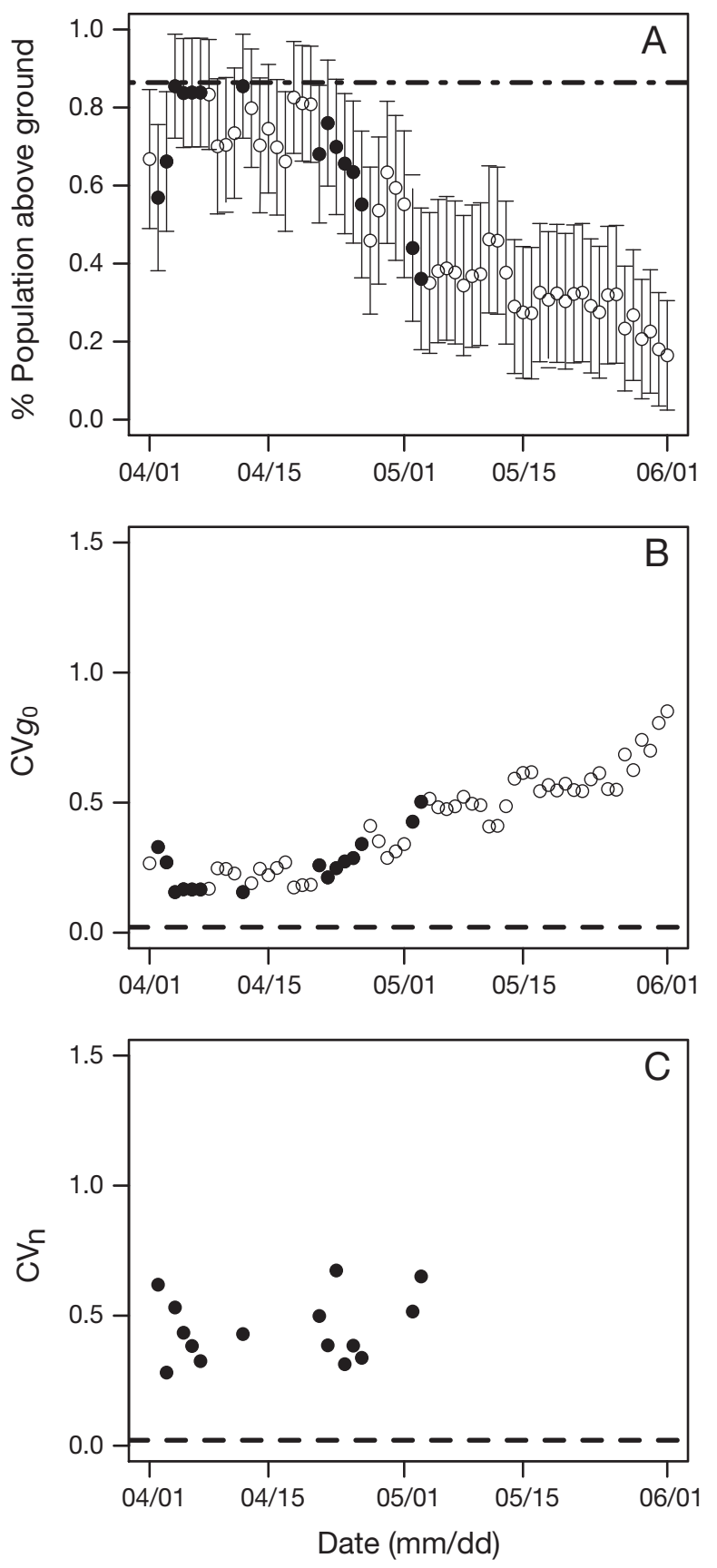

Fig. 1. (A) Daily mean sampling availability $\left(g_{0}\right.$, indicated as $\%$ of population above ground; O) for 2 study sites from 1 April to 1 June during $05: 00 \mathrm{~h}$ to $19: 00 \mathrm{~h}$, and days when transect sampling was conducted in the Western Mojave Recovery Unit $(\bullet)$. Error bars: \pm 1 SE. The dashed line represents the published estimate of $g_{0}(0.864)$ for 2004 (US Fish and Wildlife Service 2006). (B) Daily CVs of $g_{0}$ for both study sites from 1 April to 1 June. The dashed line represents the published estimate of the CV of $g_{0}(0.02)$ for 2004 (US Fish and Wildlife Service 2006). (C) Daily CVs of $n$ (the number of animals encountered per transect) on days when transect sampling was conducted in the Western Mojave Recovery Unit in 2004. The dashed line represents the CV from the range-wide estimate of $g_{0}(0.021)$ for 2004 (US Fish and Wildlife Service 2006) 

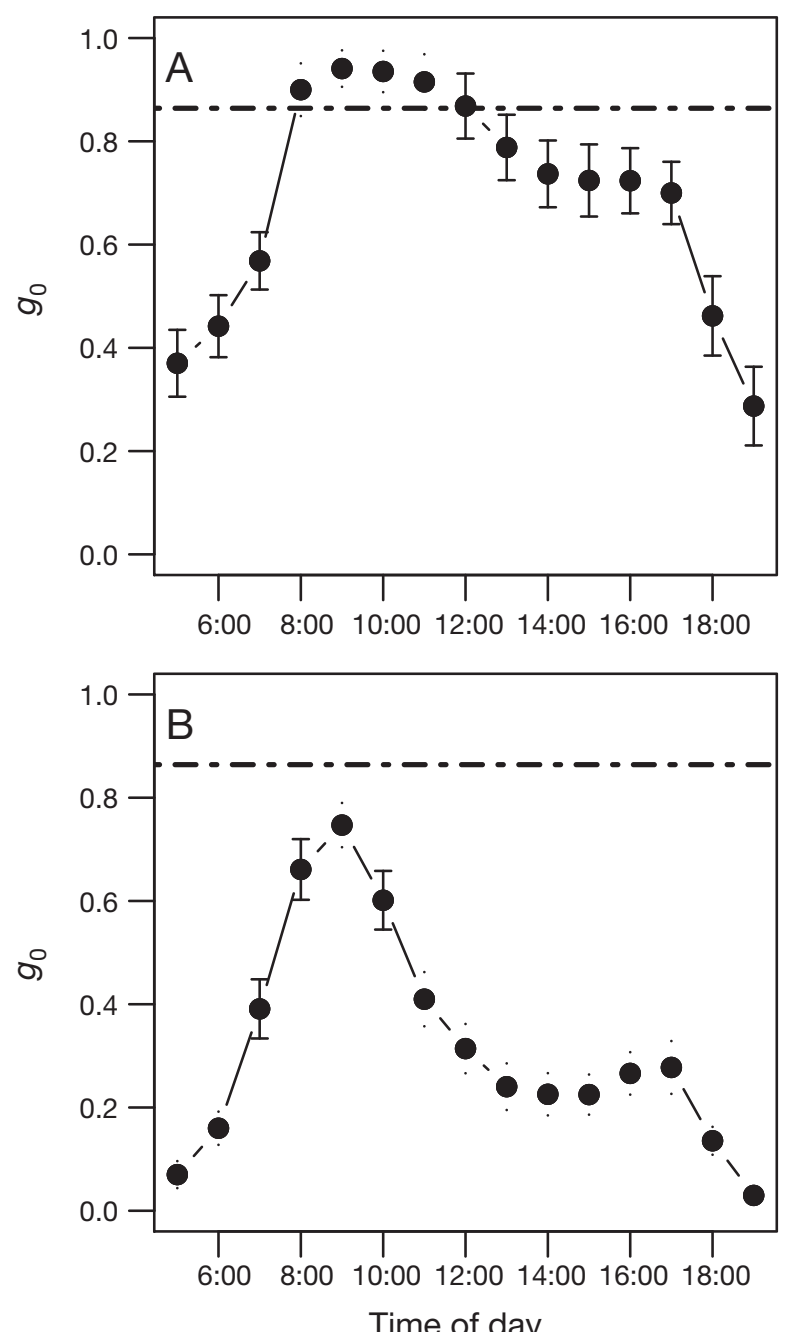

Fig. 2. Mean hourly activity $( \pm 95 \% \mathrm{CI})$ in, $g_{0},(\mathrm{~A})$ April and (B) May from 05:00 $\mathrm{h}$ to $19: 00 \mathrm{~h}\left(\mathrm{~N}=57\right.$ predictions $\left.\mathrm{d}^{-1}\right)$. The dashed lines represent the range-wide estimate of $g_{0}(0.864)$ for 2004 (US Fish and Wildlife Service 2006). Error bars are shown with dots when too small for plotting

period(s) started and the length of the sampling period(s) used to estimate $g_{0}$. Sampling periods that were started earlier in the year and were shorter in duration were more likely to occur on days when the $\mathrm{CV}$ of $g_{0}$ was low and when $g_{0}$ was high (Figs. 1B \& 3). In contrast, the $g_{0}$ for a longer sampling period that started later in the season was more likely to have a larger CV due to the substantial downward trend in activity that we observed throughout the activity season (Fig. 1A).

If sampling had occurred on the 5 consecutive days with the lowest CVs of $g_{0}$, the CV for $g_{0}$ might have been as low as 0.16 (Fig. 3). Sampling over the 25 consecutive days when $g_{0}$ was the highest yielded CVs for $g_{0}$ near 0.6 , although when sampling occurred on 5 consecutive days with very high CVs for $g_{0}$ (found

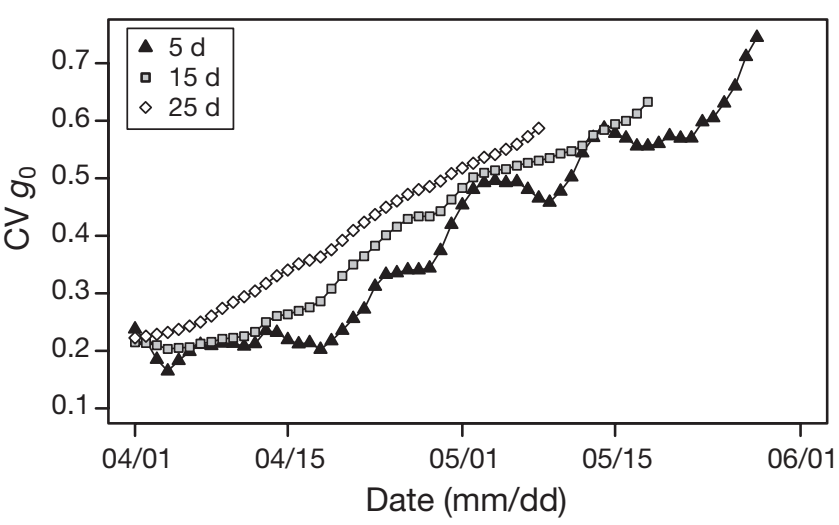

Fig. 3. Mean CVs for sampling availability $\left(g_{0}\right)$ at $5(\mathbf{\Lambda}), 15(\square)$, and $25 \mathrm{~d}(\diamond)$ sampling periods for the Western Mojave Recovery Unit in 2004. Each datum represents the CV for the sampling period starting on the indicated date

towards the end of the active season, Fig. 1B) a CV above 0.7 could be found. Thus, an expected range for the CV of $g_{0}$ of 0.16 to 0.74 was used to bracket the best and worst sampling conditions.

The CVs of $\mathrm{n}$ varied substantially from day to day depending on the number of animals encountered and the length of the transect walked. During the $15 \mathrm{~d}$ when sampling was conducted in the Western Mojave Recovery Unit, the CVs of $\mathrm{n}$ ranged from 0.28 to 0.67 . We used $0.1,0.4$, and 0.7 to bracket the best and worst sampling conditions expected under similar sampling scenarios. The CVs of $P_{a}$ from the first $5 \mathrm{yr}$ of transect sampling ranged from 0.02 to 0.05 (US Fish and Wildlife Service 2006), and again, this range was used to bracket the best and worst sampling conditions.

Using the expected ranges of the CVs for $g_{0}, P_{a}$ and $\mathrm{n}$, we calculated a possible range for the $\mathrm{CV}$ of the density estimate of 0.32 to 0.99 . Under the best sampling conditions (i.e. $g_{0}$ is high and not variable, $P_{a}$ is high and not variable, and $\mathrm{n}$ is high and consistent among transects), distance sampling as implemented for the first $5 \mathrm{yr}$ of sampling would have the power to detect annual trends in population density of $3 \%$ or more (Nussear \& Tracy 2007). This would not enable detection of what is thought to be the highest reasonable growth in desert tortoise populations (i.e. 0.5 to $1 \% \mathrm{yr}^{-1}$, US Fish and Wildlife Service 1994), but instead, would only have the power to detect trends in population decline that were $>3 \% \mathrm{yr}^{-1}$ (Fig. 4). However, under some of the worst sampling scenarios (CV of density $\sim 0.9$ ), transect sampling would not have the power to detect any meaningful trend at all.

Because the CVs for $P_{a}$ are reportedly very low (US Fish and Wildlife Service 2006), i.e. the maximum published CV is 0.05 , it is reasonable to assume that 
obtaining precise estimates of density will require conducting transect sampling during periods of high and consistent $g_{0}$. We observed a CV for $g_{0}$ of 0.26 when transect sampling in 2004 occurred on 15 nonconsecutive days, in a very wet (and active) sampling season.

\section{DISCUSSION}

Mojave Desert tortoise populations have suffered marked declines throughout their range, and in response, efforts are being implemented to promote recovery of the species. Desert tortoises are a long- lived species with delayed maturity and iteroparous reproduction and, as such, population recovery rates are expected to be slow, with upper estimates of $0.5 \% \mathrm{yr}^{-1}$ (US Fish and Wildlife Service 1994), if recovery is at all possible (Doak et al. 1994). Under these circumstances, detecting recovery (i.e. subtle increasing trends) in desert tortoise populations requires precise estimates of population density (Nussear \& Tracy 2007). Distance sampling is currently employed to estimate density of desert tortoises, and the precision of the resulting density estimates relies on the precision of 3 parameters: $g_{0}$ (availability for sampling), n (number of animals encountered per transect), and $P_{a}$ (de-
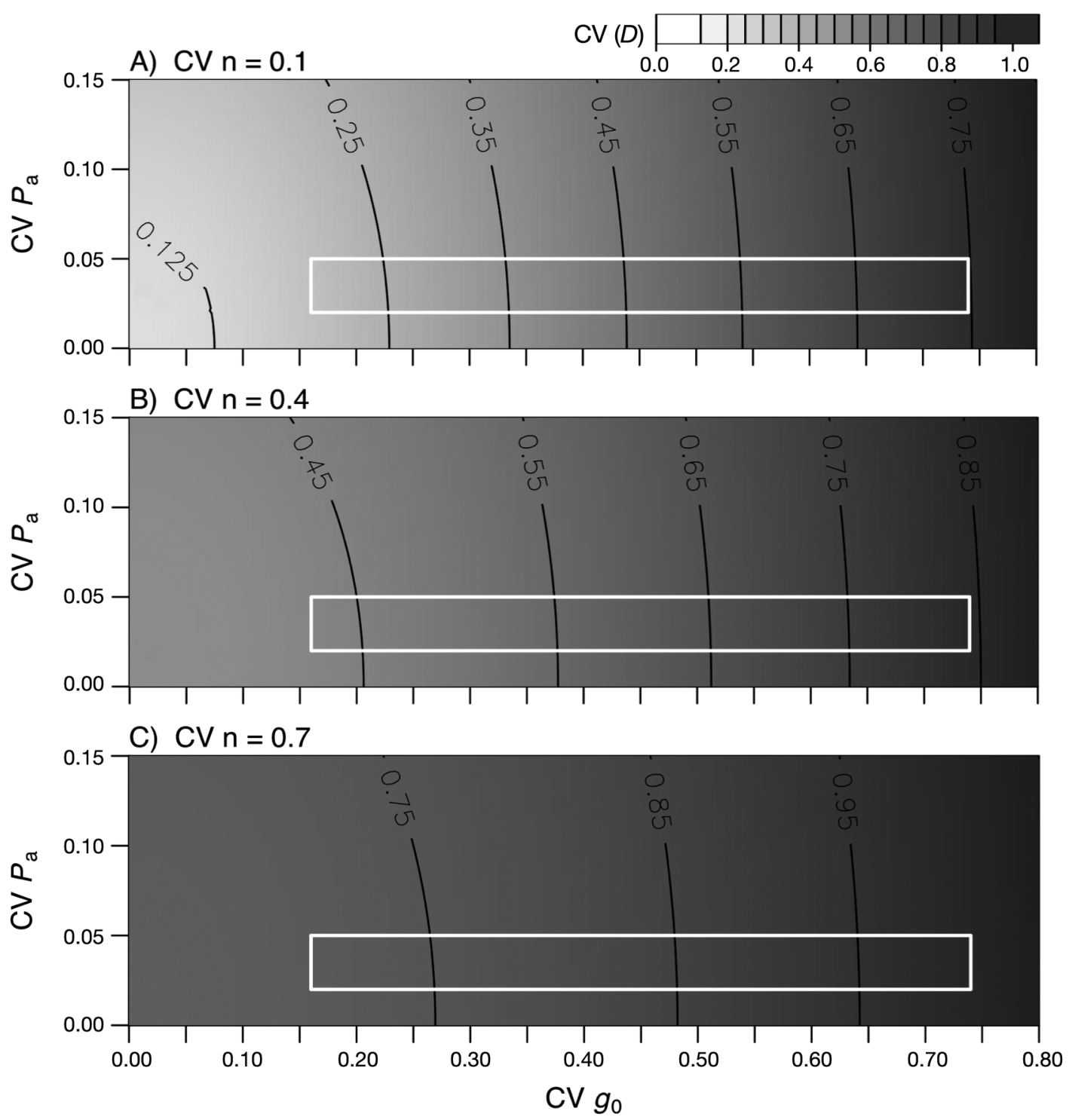

Fig. 4. CVs of the density estimate at different levels of CV of $\mathrm{n}$ (the number of animals encountered on transects; (A) 0.1 , (B) 0.4 , and (C) 0.7), CVs for $g_{0}$ (sampling availability) and CVs for $P_{a}$ (the detectability of tortoises given their availability). The black contour lines shown at $0.125,0.25,0.35,0.45$, and 0.55 , correspond with the CVs needed to detect a $1,2,3,4$ or $5 \%$ linear trend in population density as given in Nussear \& Tracy (2007). The white box represents the expected ranges of the CVs for $g_{0}$ and $P_{a}$ from the minimum and maximum values published $\left(P_{a i}\right.$ US Fish and Wildlife 2006) and observed $\left(g_{0 i}\right.$ present study) 
tectability of tortoises given their availability). These parameters can be estimated using different methods, all of which impact our ability to obtain precise density estimates while properly accounting for the observed variance in behavior, detectability and the numbers of tortoises encountered in a given sampling area.

Because we observed high daily variation in availability as the sampling season progressed, we chose to use a daily method to estimate density and its variance. When comparing the density estimate derived to account for this daily variation with the density estimate reported by the FWS (US Fish and Wildlife Service 2006), we found the 2 estimates of density to be similar, but with significantly different CVs. The reported $\mathrm{CV}$ of the density estimate for the Western Mojave Recovery Unit was substantially lower than the CV that we calculated, indicating a discrepancy in the perceived precision of the density estimates from the published report (US Fish and Wildlife Service 2006), which reflects reductions in variation when parameter estimates are pooled for the entire range and season.

The pooled estimates of $g_{0}$ and its SE (used by FWS) are derived from observations of radio-tracked tortoises in focal populations throughout the entire range for the Mojave population of desert tortoises (as opposed to just the Western Mojave Recovery Unit) for all days of sampling. The pooled estimate of $g_{0}$ is calculated as the mean of each focal animal's availability to be sampled from the 10 to 20 times it is observed during the entire sampling season, and does not reflect the variation we observed throughout the sampling period. In addition, it ignores temporal and spatial differences among populations in different regions, which we believe is an important source of variability to account for. In general terms, the pooled estimate of $g_{0}$ is a measure of the difference among individuals in their sampling availability.

It is not enough to know that 1 individual was unlike another with respect to how much time they were available to be sampled throughout the sampling period. Instead, one must know how unlike the first week of April is from the last week of April or how unlike $05: 00 \mathrm{~h}$ is from 13:00 $\mathrm{h}$ with respect to the proportion of the population that is available to be sampled. Tortoises are not the only organisms that exhibit daily or hourly changes in their availability and subsequent detectability, which adds difficulty to sampling efforts. Other survey methods (e.g. aerial surveys on a variety of species, ranging from kangaroos to larger animals including elephants and whales) use behavioral models to predict $g_{0}$ due to changes in daily or seasonal temperature or other environmental conditions that relate to sampling availability (Bayliss \& Giles 1985, Jachmann 2002, Skaug et al. 2004). However, these behavioral models are often derived from small samples or incomplete sampling (Southwell et al. 2008), which likely adds to the uncertainty of the resulting estimates of density.

In addition, the behavior of individuals is unlikely to be uniform across the entire range, such that activity in some regions may be lower than that in other regions. This adds error to the estimate of density that is not accounted for when range-wide and pooled estimates of $g_{0}$ are used, and should be considered for further study. Surely, there are interactions between topography, habitat type, climate, region and behavior that influence the number of animals observed on transects, which have yet to be enumerated or studied. While we did not find our estimate of density to be different from the published estimate (which used pooled values), the variance of the estimates differed markedly, and was largely attributable to the increased variability imparted by the reduced numbers of tortoises encountered on any given day.

The variation in numbers of encounters on transects can be caused by many factors including spatial aggregation of animals with respect to transects, and temporal clustering of availability as when portions of transects are walked when tortoises are inactive. Aggregated dispersions of individuals are known to affect estimates of density in numerous species and sampling situations (Cochran 1977, Green \& Young 1993, Christman 2004) and can certainly violate underlying assumptions of spatially uniform distributions in the computation of population density with distance sampling. Clumped species distributions can cause artificially reduced estimates of animal density when the clumped groups are missed completely during sampling (Thompson 1991, Thompson \& Seber 1994). The degree of spatial clustering in desert tortoises has only been cursorily investigated in a few localities, but evidence suggests spatial aggregation in desert tortoise distributions at multiple scales (Duda et al. 2002).

Another difference between the 2 methods used to estimate $g_{0}$ is found in the definition of 'availability' itself. The FWS defined availability as the visibility of any tortoise in the open, in vegetation, or even in a burrow (and often with the aid of a light source), because such as definition increases the total number of potential observations on each transect (thereby increasing n). Including 'visible' animals on each transect certainly increases the precision of the detection function, but it also introduces an additional error into $g_{0}$ by confounding the effects of $g_{0}$ with those of $P_{a}$. For example, tortoises on the surface would likely have different detectability than tortoise burrows, and certainly different detectability than tortoises within burrows once burrows are detected. Unfortunately, the lack of data on the detectability of burrows precludes quantifying this additional error which is not addressed here. 
While we did not explore different methods to estimate $P_{a}$, there are several sources of error that may influence its estimation and its variance that are worth discussing. For example, $P_{a}$ is partly influenced by vegetation density, such that when vegetation is lush or dense, $P_{a}$ is likely to be reduced due to an observer's inability to see through or beyond nearby vegetation. This influences observations of animals and their burrows, which confounds $P_{a}$ with $g_{0}$ especially when animals that are below the ground (but visible) are pooled with those found above the ground. The reported range-wide $P_{a}$ for 2005 was the lowest for the $5 \mathrm{yr}$ period, and also corresponded with the highest winter precipitation from the year 2000 to 2005. While wet years may correspond with high $g_{0}$, they may also correspond with depressed $P_{a}$. This may translate into additional and unmeasured variation in $P_{a}$ when vegetation density and lushness decline throughout the sampling period or when vegetation density varies throughout the sampling area, which is likely to occur when sampling over large areas such as the Mojave Desert. There are other factors that add variation to $P_{a}$ such as differences among observer experiences (Freilich \& LaRue 1998), and climate or site differences (Duda et al. 1999, Freilich et al. 2000), all of which should be accounted for to derive accurate estimates of detectability and its error.

We estimated the CV of the density estimate for 2004 in the Western Mojave Recovery Unit to be 0.53 . This would only allow for detection of population trends no smaller than $\sim 5 \% \mathrm{yr}^{-1}$ (and this could only occur as long as conditions remained the same each year). It is highly unlikely that sampling conditions better than those found in 2004 would persist for multiple years without substantial changes in sampling methods. However, if changes in sampling methods could ensure that transect sampling occurred over shorter periods when $g_{0}$ was high and less variable, CVs in $g_{0}$ as low as 0.16 might be possible. When combined with the lowest variation in $P_{a}$ and n (this occurs when sampling is conducted on fewer days when $g_{0}$ is high), estimates of density with CVs as low as 0.32 could result. This level of precision under an optimal sampling scenario would have sufficient precision to detect population trends of $3 \% \mathrm{yr}^{-1}$. Detecting trends of $3 \% \mathrm{yr}^{-1}$ may be as good as transect sampling can ever achieve when estimates of density require knowledge of the proportion of the population available to be sampled. However, this level of precision provides only a means to detect population declines, which can occur at very rapid rates (Berry 1984, US Fish and Wildlife Service 1994, Longshore et al. 2003, Tracy et al. 2004). This is because even under the best population demographics, trends in desert tortoise population growth are thought to be $<1 \%$ (Doak et al. 1994, US Fish and
Wildlife Service 1994), indicating that if managers hope to detect positive population growth, density estimates with CVs of $<0.125$ are needed. This seems infeasible using the sampling methods implemented from 2001 to 2005.

Acknowledgements. We thank A. Chesley, J. Cook, and C. Kerley for help with fieldwork, and the University of Redlands, the Clark County Desert Conservation Plan and the US Geological Survey for funding. Earlier versions of this manuscript benefitted from the reviews of S. Jenkins and P. Weisberg. We also thank the USFWS Desert Tortoise Recovery Office for access to the Western Mojave Recovery Unit monitoring data that we used for comparisons. All research using animals was conducted according to IACUC guidelines (University of Nevada IACUC Protocols A03/04-41), State (CDFG 801167-01) and Federal (TE-0706710-4) permits. Any use of trade names or specific products is for descriptive purposes only and does not imply endorsement by the US Government. This research was part of a thesis submitted to the Department of Biology at the University of Nevada, Reno.

\section{LITERATURE CITED}

Anderson DR, Burnham KP, Lubow BC, Thomas L, Corn PS, Medica PA, Marlow RW (2001) Field trials of line transect methods applied to estimation of desert tortoise abundance. J Wildl Manag 65:583-597

> Bächler E, Liechti F (2007) On the importance of $g(0)$ for estimating bird population densities with standard distancesampling: implications from a telemetry study and a literature review. Ibis 149:693-700

Bayliss P, Giles J (1985) Factors affecting the visibility of kangaroos counted during aerial surveys. J Wildl Manag 49:686-692

Berry KH (1984) The status of the desert tortoise (Gopherus agassizii) in the United States. Publication No. 113100083-81: Report from the Desert Tortoise Council to US Fish and Wildlife Service, Sacramento, CA

Buckland ST (1985) Perpendicular distance models for line transect sampling. Biometrics 41:177-195

Buckland ST, Anderson DR, Burnham KP, Laake JL, Borchers DL, Thomas L (2001) Introduction to distance sampling: estimating abundance of biological populations. Oxford University Press, New York

Buckland ST, Anderson DR, Burnham KP, Laake JL, Borchers DL, Thomas L (2004) Advanced distance sampling: estimating abundance of biological populations. Oxford University Press, New York

Bulova SJ (1994) Patterns of burrow use by desert tortoises: gender differences and seasonal trends. Herpetol Monogr 8:133-143

Bulova SJ (2002) How temperature, humidity, and burrow selection affect evaporative water loss in desert tortoises. J Therm Biol 27:175-189

Bury RB, Corn PS (1995) Have desert tortoises undergone a long-term decline in abundance? Wildl Soc Bull 23:41-47

Christman MC (2004) Sequential sampling for rare or geographically clustered populations. In: Thompson WL (ed) Sampling rare or elusive species: concepts, designs, and techniques for estimating population parameters. Island Press, Washington, DC, p 134-135

Cochran WG (1977) Sampling techniques. Wiley and Sons, New York 
Corn PS (1994). Recent trends in desert tortoise populations in the Mojave Desert. In: Bury RB and Germano DJ (eds) Biology of North American tortoises. US Department of the Interior, National Biological Survey, Fish Wildl Res 13:85-93

Doak D, Kareiva P, Klepetka B (1994) Modeling population viability for the desert tortoise in the western Mojave Desert. Ecol Appl 4:446-460

Duda JJ, Krzysik AJ, Freilich JE (1999) Effects of drought on desert tortoise movement and activity. J Wildl Manag 63: 1181-1192

Duda JJ, Krzysik AJ, Meloche JM (2002) Spatial organization of desert tortoises and their burrows at a landscape scale. Chelonian Conserv Biol 4:387-397

Fielding AH, Bell JF (1997) A review of methods for the assessment of prediction errors in conservation presence/absence models. Environ Conserv 24:38-49

Freilich JE, LaRue EL (1998) Importance of observer experience in finding desert tortoises. J Wildl Manag 62: 590-596

Freilich JE, Burnham KP, Collins CM, Garry CA (2000) Factors affecting population assessments of desert tortoises. Conserv Biol 14:1479-1489

Germano DJ, Bury RB, Esque TC, Fritts TH, Medica PA (1994) Range and habitats of the desert tortoise. In: Bury RB, Germano DJ (eds) Biology of North American tortoises. US Department of the Interior, National Biological Survey, Fish Wildl Res 13:73-84

Green RH, Young RC (1993) Sampling to detect rare species. Ecol Appl 3:351-356

Jachmann H (2002) Comparison of aerial counts with ground counts for large African herbivores. J Appl Ecol 39: 841-852

Laake JL, Borchers DL (2004) Methods for incomplete detection at distance zero. In: Buckland ST, Anderson DR, Burnham KP, Laake LJ, Borchers DL, Thomas L (eds) Advanced distance sampling: estimating abundance of biological populations. Oxford University Press, Oxford, p 108-109

Lande R (1993) Risks of population extinction from demographic and environmental stochasticity and random catastrophes. Am Nat 142:911-927

Longshore KM, Jaeger JR, Sappington JM (2003) Desert tortoise (Gopherus agassizii) survival at two eastern Mojave Desert sites: death by short-term drought? J Herpetol 37:169-177

Miller GE (1991) Asymptotic test statistics for coefficients of variation. Commun Stat A-Theor 20:3351-3363

Nussear KE, Tracy CR (2007) Can modeling improve estimation of desert tortoise population densities? Ecol Appl 17: 579-586

Nussear KE, Esque TC, Tracy CR (2002) A method for continuously measuring body temperature in terrestrial chelonians. Herpetol Rev 33:114-116

Skaug HJ, Oien N, Schweder T, Bothun G (2004) Abundance of minke whales (Balaenoptera acutorostrata) in the north-

Editorial responsibility: David Hodgson,

University of Exeter, Cornwall Campus, UK east Atlantic: variability in time and space. Can J Fish Aquat Sci 61:870-886

Southwell C, Paxton CGM, Borchers D, Boveng P, de la Mare W (2008) Taking account of dependent species in management of the Southern Ocean krill fishery: estimating crabeater seal abundance off east Antarctica. J Appl Ecol 45:622-631

Thomas L, Laake JL, Strindberg S, Marques FFC and others (2004) Distance 5.0. Release 1. Research Unit for Wildlife Population Assessment, University of St. Andrews

> Thompson SK (1991) Stratified adaptive cluster sampling. Biometrika 78:389-397

> Thompson WL (2002) Towards reliable bird surveys: accounting for individuals present but not detected. Auk 119: $18-25$

$>$ Thompson SK, Seber GAF (1994) Detectability in conventional and adaptive sampling. Biometrics 50:712-724

Tracy CR, Averill-Murray R, Boarman WI, Delehanty D and others (2004) Desert tortoise recovery plan assessment. p 217, www.fws.gov/Nevada/desert_tortoise/documents/ dtrpac/dtrpac_report.pdf

Turner RM (1982) Mohave desertscrub. In: Brown DE (ed) Biotic communities of the American Southwest - United States and Mexico. Desert Plants 4:157-168

US Fish and Wildlife Service (1989) Endangered and threatened wildlife and plants; emergency determination of endangered status for the Mojave population of the desert tortoise. Fed Regist 54:32326-32331

US Fish and Wildlife Service (1990) Endangered and threatened wildlife and plants; determination of threatened status for the Mojave population of the desert tortoise. Fed Regist 55:12178-12191

US Fish and Wildlife Service (1994) Desert tortoise (Mojave population) recovery plan. US Fish and Wildlife Service, Portland, OR, p 73

US Fish and Wildlife Service (2006) Range-wide monitoring of the Mojave population of the desert tortoise: 2001-2005 summary report. Report by the Desert Tortoise Recovery Office, US Fish and Wildlife Service, Reno, NV

US Fish and Wildlife Service (2008) Draft revised recovery plan for the Mojave population of the desert tortoise (Gopherus agassizii). US Fish and Wildlife Service, California and Nevada Region, Sacramento, CA, p 209

Wilson DS, Morafka DJ, Tracy CR, Nagy KA (1999) Winter activity of juvenile desert tortoises (Gopherus agassizii) in the Mojave Desert. J Herpetol 33:496-501

Woodbury AM, Hardy R (1948) Studies of the desert tortoise, Gopherus agassizii. Ecol Monogr 18:146-200

Zimmerman LC, O'Connor MP, Bulova SJ, Spotila JR, Kemp SJ, Salice CJ (1994) Thermal ecology of desert tortoises in the eastern Mojave Desert: seasonal patterns of operative body temperatures, and microhabitat utilization. Herpetol Monogr 8:45-59

Submitted: February 3, 2009; Accepted: June 12, 2009

Proofs received from author(s): August 31, 2009 